\title{
INVESTIGATION ON POSSIBLE USE OF PALM NUTSHELLS AS REDUCTANT FOR THE REDUCTION OF COPPER SLAG FOR COPPER RECOVERY
}

\author{
Michel Kalenga WA KALENGA, Motshoea THUNKA, Didier Kasongo NYEMBWE \\ Department of metallurgy, School of mining, metallurgy and chemical engineering, Faculty of Engineering \\ and Built Environment, University of Johannesburg, Doornfontein, South Africa, michelk@uj.ac.za
}

https://doi.org/10.37904/metal.2020.3633

\begin{abstract}
The depletion of ores from the first sources on one hand has led to using damped materials that contain valuable metals to be recycled while environmental threats are being targeted and on the other hand high price of reductant coupled with their depletion have caused a stir in the metallurgical industry. Many slags are currently recycled for the recovery of valuable metals while new reductants are being tested for eventually replace the generic reductants. In this work, copper slag from Water-jacket furnace have been used to recover copper in presence of raw palm nutshells as possible replacement of generic reductants. Characterisation of the copper slag, the palm nutshells and products were conducted using XRD, XRF and SEM-EDS. Results have shown that dominants elements in the slag were $\mathrm{Fe} 33.83 \mathrm{wt} \%$, Zn $6.73 \mathrm{wt} \%$, Cu $1.26 \mathrm{wt} \%$. Raw palm nutshells analyses revealed $6.39 \mathrm{wt} \%$ moisture, $61.56 \mathrm{wt} \%$ volatile matters and $4.35 \mathrm{wt} \%$ ash content while fixed carbon amounted to be $27.89 \%$ and loss of ignition (LOI) $91.8 \%$. The reduction experiments were conducted in a horizontal tube furnace at $1300{ }^{\circ} \mathrm{C}$ under argon to create an inert environment and efficiently test the reducing capability of the palm nutshells. The composition of the metal produced revealed $41.84 \mathrm{wt} \%$ $\mathrm{Cu}, 26.41 \mathrm{wt} \%$ Co and $31.75 \mathrm{wt} \%$ Fe. However, it was noticed that the miscibility of the metal and the slag was prominent. As a first attempt, results showed very promising and further investigations are required to reveal optimums conditions.
\end{abstract}

Keywords: Metallurgy, palm nutshells, reductant, slag

\section{INTRODUCTION}

The depletion of generic reductants and the environmental constraints have opened a door to searching new reductants that would be cost effective and environmental friendly. For years biomass have been investigated for possible use in metallurgy. Investigation on the use of cow manure and wood in steel production were conducted and found that there is still much to do to get to a better understanding on how raw biomass and pretreated biomass could be effective in the production of metals [1]. The potential of use of biomass in different areas of metallurgy was also investigated and was found that biomass presented a great future [2]. Further, research on the influence of biomass on metallurgical coke was conducted and led the findings the addition of biomass had led to a considerable decreased in the plastic properties of the coal blend [3]. A trial on the use of biomass in the production of pig-iron and found that replacing $20 \%$ substitution of the fossil coal with biomass led to saving $300 \mathrm{~kg}$ of $\mathrm{CO}_{2}$-equivalent per ton of pig-iron produced or an equivalent reduction of about $15 \%$ of total greenhouse gas emissions [4]. A number of characterizations on biomass in order to find their suitability for sintering in sintering process revealed that some biomass are useful in the metallurgical industry [5]. Research on the utilization of biomass in iron production found that replacing fine coke with biomass was effective and that in sintering the quality was hampered [6]. Investigations on the use of macadamia nutshells as a possible replacement in the ferromanganese production revealed that there was great potential, but optimization parameters needed to be investigated to improve the immiscibility of the system metal/slag [7]. 
Similar reduction tests using macadamia nutshells were conducted on tin ore [8]. It was found that the use of macadamia nutshells in tin reduction was promising and further investigations were recommended. Palm Kernel Shells (PKS) were tried in the production of ferromanganese [9]. They found that the use of PKS as a reductant was better than charcoal for all stoichiometric ratios that they used. The possibility of the use of PKS in the recovery of nickel was also investigated. Results have revealed that nickel recovery was satisfactory [10]. In line with the above, the current work investigated the potential of using Palm Kernel Shell from Central Africa as a reductant to recover copper from copper slag in correlation with their composition since elements present in the KPS are very influential on the final products quality and recovery.

\section{EXPERIMENTAL}

\subsection{Materials}

A copper-slag from the water-jacket furnace, producing copper-matte, containing copper and other base metals was used for copper recovery. This slag was provided by Gecamines from the Democratic republic of Congo. Raw PKS samples were provided by artisanal palm oil producers from the Democratic Republic of Congo. Lime from the metallurgy laboratory of the University of Johannesburg. It was used as a flux to increase the basicity of the feed to one.

\subsection{Equipment and methodology}

Experiments were conducted using a vertical alumina tube furnace at $1400^{\circ} \mathrm{C}$ with a heating rate of $7{ }^{\circ} \mathrm{C} / \mathrm{min}$. A graphite crucible was used for the experiment. A layer of raw PKS was placed at the bottom and on the side of the inside of the graphite crucible to limit the interference of graphite into the reduction reactions.

The characterization was conducted using X-Ray Fluorescence (XRF), X-ray Diffraction (XRD) and Scanning Electron Microscope (SEM-EDS) for the slag sample whereas proximate and ultimate analysis was conducted on the raw PKS to determine fixed carbon and other matters present as well as the moisture.

The stoichiometric amount with $5 \%$ excess of raw PKS for the reduction of copper was added to the slag sample and milled together with the added lime for 15 minutes for better homogenization. Argon was blown into the furnace for the whole duration of the experiment. The sample was kept into the furnace for 1 hour after the furnace has reached the aimed temperature, then switched-off under argon down to room temperature, products were collected and analyzed.

\section{RESULTS AND DISCUSSION}

The elemental XRF results of the raw copper slag are presented in Table 1 below.

Table 1 XRF results of the copper slag

\begin{tabular}{|c|c|c|c|c|c|c|c|c|c|}
\hline Element & $\mathbf{M g}$ & $\mathbf{A l}$ & $\mathbf{S i}$ & $\mathbf{C a}$ & $\mathbf{K}$ & $\mathbf{F e}$ & $\mathbf{C o}$ & $\mathbf{C u}$ & $\mathbf{Z n}$ \\
\hline $\mathbf{w t} \%$ & 2.9 & 3.29 & 18.15 & 22.11 & 1.11 & 33.83 & 2.19 & 6.26 & 6.73 \\
\hline
\end{tabular}

The XRF elemental composition of the raw copper slag revealed that Fe was the most abundant element in the slag followed by $\mathrm{Ca}$. During the matte production, silica was added to the water-jacket furnace for iron slagging. This implied the formation of fayalite in the slag to avoid the formation of magnetite that has a high melting temperature which could disturb matte production. The copper, cobalt and zinc content were also found high enough. This made this slag a copper-bearing material that could serve for the recovery of copper.

Figure 1 below presents the SEM results of the slag head sample while the microscopic analysis of the SEM is provided in Table 2. 


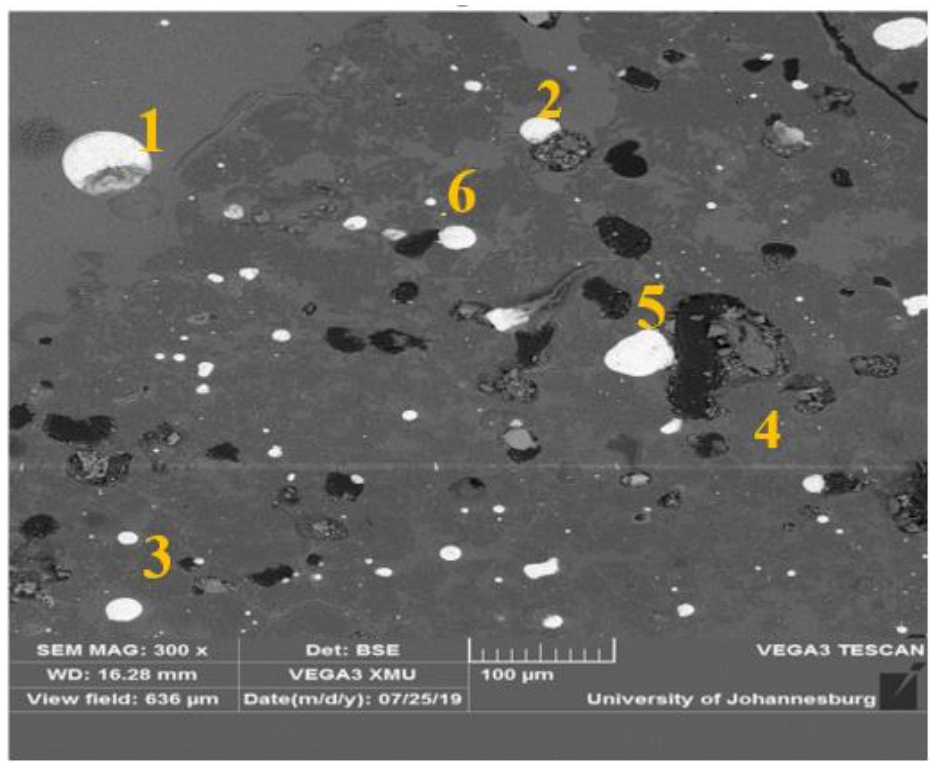

Figure 1 Microstructure of the copper slag (SEM)

From Table 2, it can be noted that the slag is fayalitic or a silicate slag with a low basicity since silica is dominant as opposed to basic compounds in the sample. Results also revealed the presence of delafossite which is a double oxide of copper and iron. Further, the presence of olivine has been depicted. This is a proof of presence phases where calcium and magnesium dissolved. However, form different spectra, it is observed that basic oxide are low in amounts than acidic oxides. This implies that the slag is more acidic.

Table 2 SEM results of the copper slag (wt\%)

\begin{tabular}{|c|c|c|c|c|c|c|c|c|c|c|c|l|}
\hline Element & $\mathbf{M g}$ & $\mathbf{A l}$ & $\mathbf{S i}$ & $\mathbf{C a}$ & $\mathbf{K}$ & $\mathbf{F e}$ & $\mathbf{C o}$ & $\mathbf{C u}$ & $\mathbf{Z n}$ & $\mathbf{P b}$ & $\mathbf{0}$ & \multicolumn{1}{|c|}{ Phase } \\
\hline Spectrum 1 & 3.9 & 3.6 & 21.6 & 4.4 & 0.3 & 33.8 & 2.2 & 6.3 & 1.1 & 3.0 & 39.2 & Fayalite, cuprite diopside, olivine \\
\hline Spectrum 2 & 1.7 & 1.5 & 9.0 & 1.8 & 0.2 & 8.8 & 1.4 & 0.6 & 1.3 & 0.6 & 1.3 & Fayalite, cuprite diopside, olivine \\
\hline Spectrum 3 & - & - & 6.2 & - & - & 2.4 & - & 69.3 & - & - & 24.5 & Delafossite \\
\hline Spectrum 4 & 4.1 & 3.8 & 22.6 & 4.3 & 0.3 & 17.9 & 2.8 & - & 3.8 & 0.7 & 40 & Fayalite, cuprite diopside, olivine \\
\hline Spectrum 5 & 5.2 & 4.5 & 25.3 & 10.6 & 0.6 & 7.0 & 0.4 & 0.6 & 0.3 & - & 44.6 & Fayalite, cuprite diopside, olivine \\
\hline Spectrum 6 & - & 7.1 & 31.0 & - & - & - & - & 11.0 & - & - & 44.4 & Delafossite, diopside \\
\hline
\end{tabular}

Table 3 below presents the chemical composition of the raw KPS. It is observed that only very little amount of zinc is present among the base metals and low amount of iron as opposed to what was found in the copper slag. It is observed that only very little amount of zinc is present among the base metals and low amount of iron as opposed to what was found in the copper slag. This does not have an influential effect on the activities of the two elements. However, $\mathrm{Si}$ and $\mathrm{Ca}$ might have an influence on the amount of lime to add for the adjustment of the basicity of the feed to one. Further, looking at the amount of PKS to be added and the ratio $\mathrm{Si} / \mathrm{Ca}$ in the PKS, the influence of Si/Ca in the PKS does not change considerably the amount of lime to be added although is taken into account. Loss on ignition (LOI) was found to be $91.8 \%$.

Table 3 XRF results of the raw PKS

\begin{tabular}{|c|c|c|c|c|c|c|c|c|c|c|c|c|c|}
\hline Element & $\mathbf{A l}$ & $\mathbf{C a}$ & $\mathbf{C l}$ & $\mathbf{C r}$ & $\mathbf{F e}$ & $\mathbf{K}$ & $\mathbf{M g}$ & $\mathbf{N a}$ & $\mathbf{S}$ & $\mathbf{S i}$ & $\mathbf{Z n}$ & $\mathbf{0}$ & LOI \\
\hline wt $\%$ & 0.3 & 0.8 & 0.7 & 0.1 & 0.5 & 0.7 & 0.2 & 0.4 & 0.2 & 1.2 & 0.2 & 2.9 & 91.8 \\
\hline
\end{tabular}




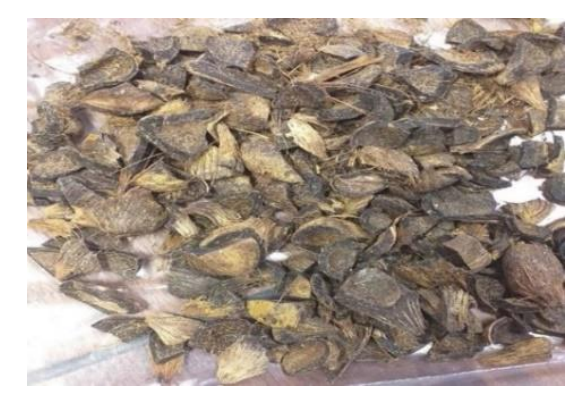

Uncleaned raw PKS

Figure 2 Images of PKS

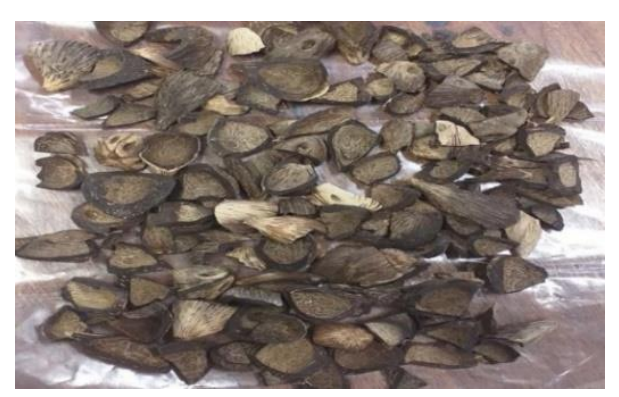

Cleaned raw PKS

The proximate analysis of the PKS is presented in Table 4 below.

Table 4 Proximate analysis of the raw PKS

\begin{tabular}{|c|c|c|c|c|c|}
\hline Element & Moisture & Volatile matters & Ash & Calorific Value & Sulphur \\
\hline $\mathbf{w t} \%$ & 6.30 & 61.56 & 4.25 & 19.57 & 0.13 \\
\hline
\end{tabular}

Fixed carbon $=100-($ moisture + Volatile matters + Ash $)=27.89 \%$

The fixed carbon is considerably high for such natural carbonaceous materials as compared to raw macadamia nut shells. Therefore, while the PKS from Central Africa are agricultural wastes, they present a great potential for their use as reductant.

Tables 5 and 6 present XRF results of the secondary slag and the produced alloy respectively. From Tables $\mathbf{5}$ and $\mathbf{6}$, it is found that no $\mathrm{Zn}$ is present. This is a confirmation that zinc evaporated and left in the offgas. It is important to mention that $\mathrm{Fe}, \mathrm{Cu}$ have tremendously decrease implying their recovery in the alloy. It is however noticed that $\mathrm{Si}$ and $\mathrm{Ca}$ have increased. This is due to the change of basicity. Co is not present in the secondary slag showing its high recovery to the alloy.

Table 5 XRF results of the secondary slag

\begin{tabular}{|c|c|c|c|c|c|c|c|c|}
\hline Element & $\mathbf{M g}$ & $\mathbf{A l}$ & $\mathbf{S i}$ & $\mathbf{S}$ & $\mathbf{K}$ & $\mathbf{C a}$ & $\mathbf{F e}$ & $\mathbf{C u}$ \\
\hline $\mathbf{w t} \%$ & 3.55 & 4.42 & 25.18 & 0.21 & 1.7 & 53.88 & 7.81 & 0.57 \\
\hline
\end{tabular}

Table 6 XRF results of the metal alloy

\begin{tabular}{|c|c|c|c|}
\hline Element & $\mathbf{F e}$ & $\mathbf{C o}$ & $\mathrm{Cu}$ \\
\hline $\mathbf{w t} \%$ & 38.01 & 2.3 & 59.4 \\
\hline
\end{tabular}

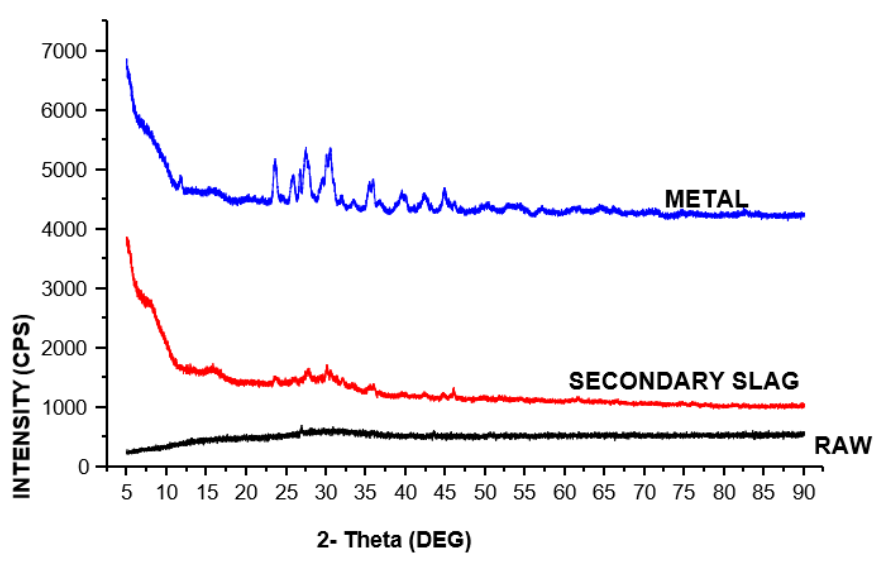

Figure 3 XRD of the alloy and secondary slag 


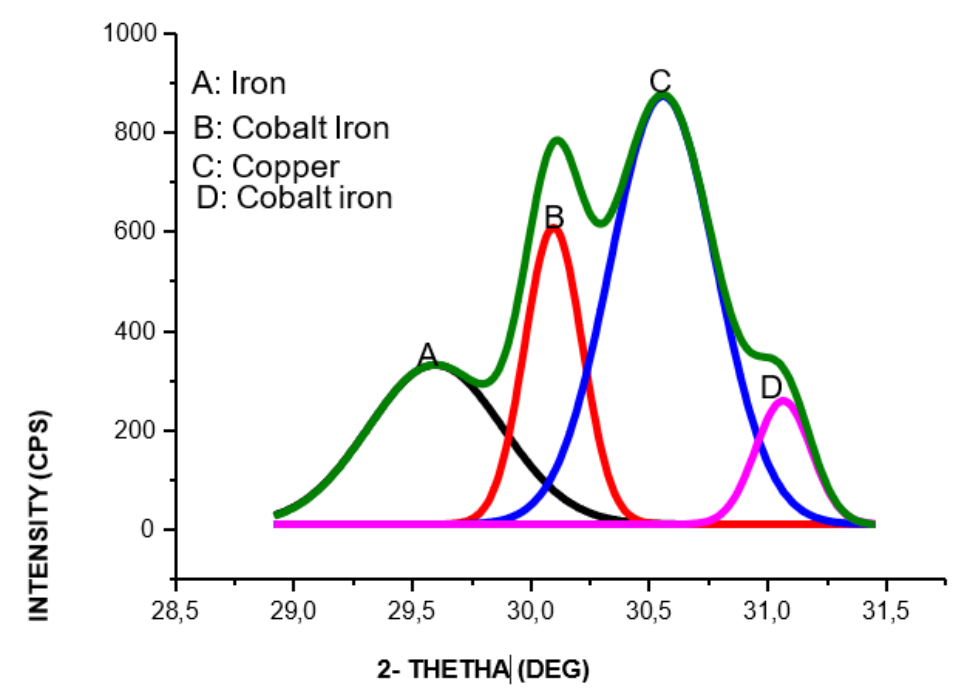

Figure 4 Decomposed XRD of the alloy and secondary slag

The XRD results of the produced alloy and the secondary slag are presented in Figures $\mathbf{3}$ and $\mathbf{4}$. For better depiction, the XRD of the alloy was decomposed using Origin 8.5 software where as the slag had too much amorphous phases and could not be easily decomposed.

Figures 3 and $\mathbf{4}$ present the XRD results of the secondary slag and the alloy produced. It is observed that the alloy produced contains $\mathrm{Cu}, \mathrm{Fe}$ and $\mathrm{Co}$. This confirmed the results obtained with XRF. It can therefore be concluded that the reduction was effective. It is also important to mention that the alloy was easily separated from the slag. This implies that the slag properties were good enough to promote the immiscibility of the two phases.

\section{CONCLUSION}

Results obtained in the current investigation have revealed that raw PKS have considerable fixed carbon content and can be used as a reductant from the agricultural waste since it has of fixed carbon content and low sulphur content. This is an advantage compared to other biomass that has low carbon fixed content and high mass of volatiles matters. The expectation for improvement in producing high quality the PKS is high. Although $\mathrm{Fe}$, Co was recovered, Cu was found to be $59.4 \mathrm{wt} \%$ in the alloy which is considerable since copperslag was used as copper bearing material. Noting that the slag is a secondary source, such level of recovery using untreated PKS, the prospect of improvement is very much promising to treat secondary sources.

The use of raw PKS led to a slag of good fluidity and good immiscibility between the metal phase and the secondary slag.

The physical properties such abrasion index and tumble index, porosity and probable shrinkage have to be thoroughly investigated to ensure the handling of PKS in furnaces. Further, gas emissions of raw PKS from Central Africa and their subsequent biochar need investigation to ensure their environmental friendliness compared to generic reductants and other biomass such as macadamia nutshells as previously found.

\section{ACKNOWLEDGEMENTS}

The authors acknowledge Gecamines and artisanal palm oil producers from Central Africa for providing the copper slag and the PKS, contributing toward generation of data made available to metallurgical industry. 


\section{REFERENCES}

[1] LU, L., Li, X., MAHONEY, M., ZHANG, Z. Biomass materials for metallurgical applications [on-line]. Advances in Materials Science and Engineering. 2018, vol. 2018. [Viewed 2020-07-07]. Available from: https://doi.org/10.1155/2018/7297136.

[2] WEI, R., ZHANG, L., CANG, D., LI, J., Li, X., XU, C.C. Current status and potential of biomass utilization in ferrous metallurgical industry. Renewable and Sustainable Energy Reviews. 2017, vol. 68, part 1, pp. 511-524.

[3] MONTIANO, M.G., DÍAZ-FAES, E., BARRIOCANAL, C., ALVAREZ, R. Influence of biomass on metallurgical coke quality. Fuel. 2014, vol.116, pp. $175-182$.

[4] FICK, G., MIRGAUX, O., NEAU, P., PATISSON, F. Using biomass for pig iron production: a technical, environmental and economical assessment. Waste and Biomass Valorization. 2014, vol. 5, no. 1, pp. 43-55.

[5] SOREN, S., JHA, G., MEHTA, K.D. Characterization and application of biomass used in metallurgical sintering operation as a fuel replacement. In $2^{\text {nd }}$ Euro Global Summit and Expo on Biomass and Bioenergy. UK, London: EIA Bioenergy, 2017.

[6] MAŠLEJOVÁ, A. In METAL 2013: 22nd International Conference on Metallurgy and Materials. Brno: TANGER, 2013.

[7] WA KALENGA, M.K., NYEMBWE, D.K., MULABA-BAFUBIANDI, A. Biomass reduction of manganese ore in presence of carbon monoxide. In $5^{\text {th }}$ International Conference COMAT 2018 "Recent Trends in Structural Materials". Pilsen: TANGER, 2018.

[8] WA KALENGA, M.K. Use of macadamia nut shells in the tin production and their effects on the slag. In COMAT 2018: $5^{\text {th }}$ International Conference COMAT 2018 "Recent Trends in Structural Materials". Pilsen: TANGER, 2018

[9] SUPRIYATNA, Y.I, ZULHAN, Z., TRIAPRIANI, Y. The ferromanganese production using Indonesian low-grade manganese ore using charcoal and palm kernel shell as reductant in mini electric arc furnace. IOP Conf. Series: Materials Science and Engineering. 2018, vol. 285. 012022 doi: https://doi.org/10.1088/1757-899X/285/1/012022.

[10] ADZHANI, S., HIDAYANTI, R., MAKSUM, A. The influence of palm kernel shell mass ratio as a reducing agent in the lateritic nickel ore carbothermic reduction process. IOP Conf. Series: Earth and Environmental Science. 2018, vol. 105. 01 2016. doi : https://doi.org/10.1088/1755-1315/105/1/012016. 